\title{
An objective view of homeopathy in Slovakia
}

\section{J. A. Spinelli III}

University of Scranton, Department of Health Administration

and Human Resources, USA

\section{Correspondence to:}

University of Scranton, Department of Health Administration, and Human Resources, 800 Linden St, Scranton, PA 18510, USA

Submitted: 16.5 .2015

Revised: 17.3 .2016

Accepted: 1.8 .2016

\section{Reviewers:}

S. Szydlowski

University of Scranton school of Education, USA

V. Okoth

Adjunct lecturer Catholic University of Eastern Africa, Nairobi, Kenya

\section{Key words:}

Alternative Medicine, Homeopathy, Healthcare

CSWHI 2016; 7(2): 47-49 @ 2016 Clinical Social Work and Health Intervention

\section{Abstract:}

Complementary and Alternative Medicine and specifically Homeopathy, have both supporters and those who feel that they have no part in the delivery of healthcare.

\section{Complementary and alternative medicine}

Complementary and Alternative Medicine (CAM) has been around for centuries. The most popular uses in Europe include acupuncture, chiropractic medicine, reflexology, the use of herbal supplements, and homeopathy (CAMDOC, 2010). Homeopathy, while not a viable replacement for clinical medicine, has gained much support and also scrutiny in recent years. The general population has become more health conscious in recent times and the holistic approach used by homeopathic practitioners is a major reason that it has gained in popularity in this author's opinion.

Proponents of homeopathy point to a few key reasons for the use of this technique. As stated, homeopathy looks at preventing and 
curing illnesses by focusing on the whole person, that is, how the mental, physical, emotional, and spiritual elements of an individual are interconnected to maintain health. There are two main principles at the heart of homeopathy, developed by Dr. Samuel Hahnemann in Germany in the $18^{\text {th }}$ Century and they are "Like Cures Like," or the Similarity Principle, and "The Law of Minimum Dose." The Similarity Principle states that a disease can be cured by a substance that produces similar symptoms in healthy people and the Law of Minimum Dose, contrary to the prescribing of pharmaceuticals, proposes that the lower the dosage of medication, the greater the effectiveness. Homeopathic doctors aim to treat each person using an individualized approach. It is their belief that no two people will react the same way to a treatment, pathogen, or stressor. By using this individualized approach, homeopathic doctors look at each person's symptoms, disease, build, temperament, and genetic predispositions (ECH, 2010). Whether one feels that these principles hold true or not, it is used by $65 \%$ of Europeans (CAMDOC, 2010) and an understanding of this branch of CAM from an objective perspective is beneficial to formulating an opinion.

Regulation of CAM, the practice of Homeopathy, and homeopathic drugs in Central Europe varies by country. There are three models that are used in regulating the practice of medicine:

Direct government-administered regulation - In most European countries, the government authorizes, registers, and supervises health professionals. In this type of regulation, the authorities can withdraw the authorization of health professionals if the law is broken.

Government-sanctioned self-regulation - In this form of regulation, the government relies on national medical associations to authorize, register, and supervise health professionals in particular disciplines.

Independent self-regulation - Self-regulation relies on the associations of individual therapies to develop their own statistics, educational and research programs, and standards of competence. (CAMDOC, 2010).

The legal status of homeopathy is unclear in Slovakia at this time (wholehealthnow.com). The practice of Homeopathy is not regulated by the government. However, homeopathic remedies that have been labeled as "drugs" are subject to government regulation.

A number of CAM and homeopathic associations exist that offer education and resources:

CAMDOC Alliance, consisting of The European Committee for Homeopathy, The European Council of Doctors for Plurality in Medicine, The International Council of Medical Acupuncture and Related Techniques, The International Federation of Anthroscopic Medical Associations.

The Slovak Homeopathic Society

The European Central Council of Homeopaths

The World Homeopathy Awareness Organization.

There are also side effects and risks involved with homeopathic remedies. Homeopaths as well as those opposed to the use of Homeopathy cite its lack of empirical data showing its effectiveness and also cited is the lack of fundamental concepts of chemistry and physics.

The National Institutes of Health in the United States lists these risks as well (nih. gov):

Homeopathic vaccination have been promoted by some supporters but these lack any data to show that they are a viable substitute for conventional immunizations. 
Many homeopathic remedies contain large amounts of active ingredients that can have adverse effects.

Replacing an effective conventional remedy with an ineffective homeopathic remedy can have adverse effects.

Many questions surround the use of Homeopathy and will continue to do so until clinical research can prove the effectiveness of many of its remedies. More research is certainly needed. Still, supporters of Homeopathy believe that it is a safe, cost-effective, and sustainable way to complement the delivery of healthcare.

\section{References}

1. CAMDOC Alliance (2010). The Regulatory Status of Complementary and Alternative Medicine for Medical Doctors in Europe.

2. European Committee for Homeopathy (2010). Homeopathic Care in a Medical Context. Brussels, Belgium.

3. Homeopathy in Slovakia, 1860 to present. (n.d.). Retrieved from http://www.wholehealthnow.com/homeopathy_pro/slovakia. html

4. Homeopathy: An Introduction | NCCAM. (n.d.). Retrieved from http://nccam.nih.gov/ health/homeopathy 